\title{
Description of a new species of the genus Caveonchus Siddiqi, 1982 (Nematoda: Dorylaimida) with diagnostic compendium and key to its species
}

\author{
S. AHAD, W. AHMAD*
}

Section of Nematology, Department of Zoology, Aligarh Muslim University, Aligarh - 202002 INDIA, *E-mail: ahmadwasim57@gmail.com

\section{Article info}

Received October 29, 2016 Accepted February 23, 2017

\begin{abstract}
Summary
Caveonchus siddiqii $\mathrm{n}$. sp. is described and illustrated based on specimens collected from both India and Japan. It is characterized by having a medium sized body ( $L=0.86-1.12 \mathrm{~mm}$ ); labial disc present; amphideal fovea flask-shaped; lip region cap-like, offset by slight constriction; odontostyle $8-9 \mu \mathrm{m}$, odontophore $10-12 \mu \mathrm{m}$; pharynx with slender anterior part which expands abruptly into the saccate basal bulb, occupying about $16-21 \%$ of total neck length; female genital system mono-opisthodelphic; anterior genital branch $70-100 \mu \mathrm{m}$ or $1.9-2.8$ times the midbody diameter long; tail short, rounded, hemispheroid, $0.5-0.7$ anal body diameter long; spicules $30-38 \mu \mathrm{m}$ long; and three spaced ventromedian supplements. Its relationship with all the known species of the genus is discussed. A diagnostic compendium and a key to identification of the species is also provided.
\end{abstract}

Keywords: Caveonchus siddiqii n. sp.; compendium; description; India; Japan

\section{Introduction}

Siddiqi (1982) proposed the genus Caveonchus, described two new species $C$. colombicus (type species) and C. brevisaccus from Colombian rain forest, and also transferred the species $\mathrm{Ba}$ sirotyleptus saccatus (Goseco et al., 1981) under it. On the basis of its pharyngeal bulb morphology and a hollow odontostyle, he placed it in the subfamily Tyleptinae Jairajpuri, 1964 under the family Leptonchidae. Loof and Zullini (2000) recorded C. saccatus from Costa Rica. Pedram et al. (2012) added a new species C. ferrisae from Northern Iran.

According to Siddiqi (1982) the genus Caveonchus occupies an intermediate position between genus Tyleptus Thorne, 1939 and Basirotyleptus Jairajpuri, 1964. The spear extension and the pharyngeal bulb are similar to Basirotyleptus, whereas, the hollow odontostyle has some similarity with Tyleptus. He also mentioned that the odontostyle of Caveonchus is similar to that of Proleptonchus Lordello, 1955. Further, Peña-Santiago (2006) placed it under Leptonchinae Thorne, 1935, because of its attenuate odontostyle with narrow but visible lumen and small aperture. Andrássy (2009) followed the same classification.

\section{Materials and methods}

The soil samples were processed using Cobb's (1918) sieving and decantation and modified Baermann's funnel techniques. The nematodes were extracted and fixed in hot formalin-glycerol fixative, dehydrated by the slow evaporation method (Seinhorst, 1959), and mounted in anhydrous glycerin. Permanent mounts were prepared using the paraffin wax ring method (de Maesneer \& d'Herde, 1963). The measurements were taken with an ocular micrometer and drawings made using a drawing tube and some of the best preserved specimens were photographed using a Nikon Eclipse 80i microscope and a Nikon DS digital camera. Raw photographs were edited using Adobe $\circledast$ Photoshop $\circledast$

\footnotetext{
* - corresponding author
} 


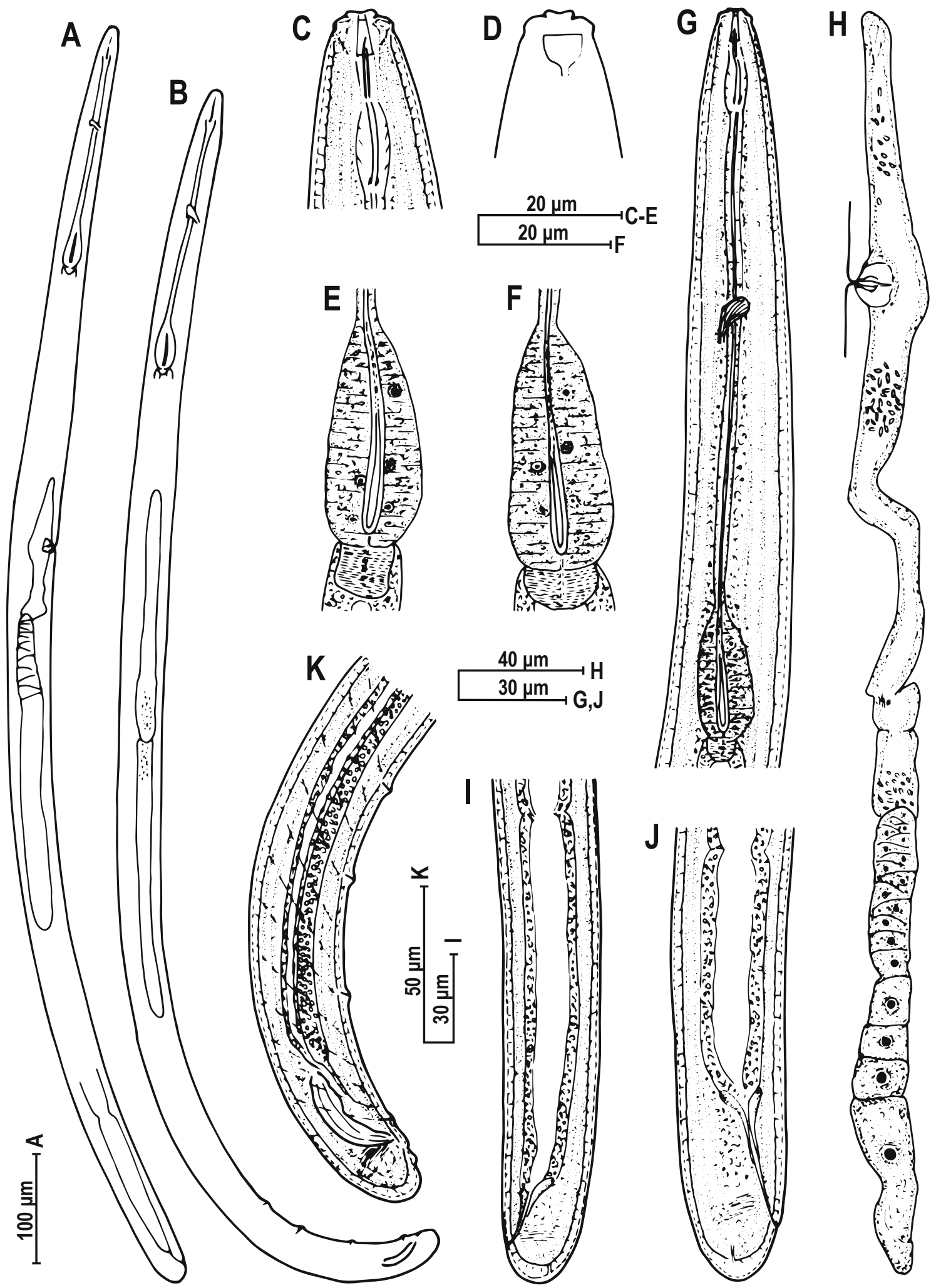

Fig. 1. Caveonchus siddiqii n. sp. (A) Entire female; (B) entire male; (C) anterior region; (D) anterior end showing amphid; (E. \& F) pharyngeal bulb; (G) pharyngeal region; (H) female genital system; (I. \& J) female posterior region; (K) male posterior region. 

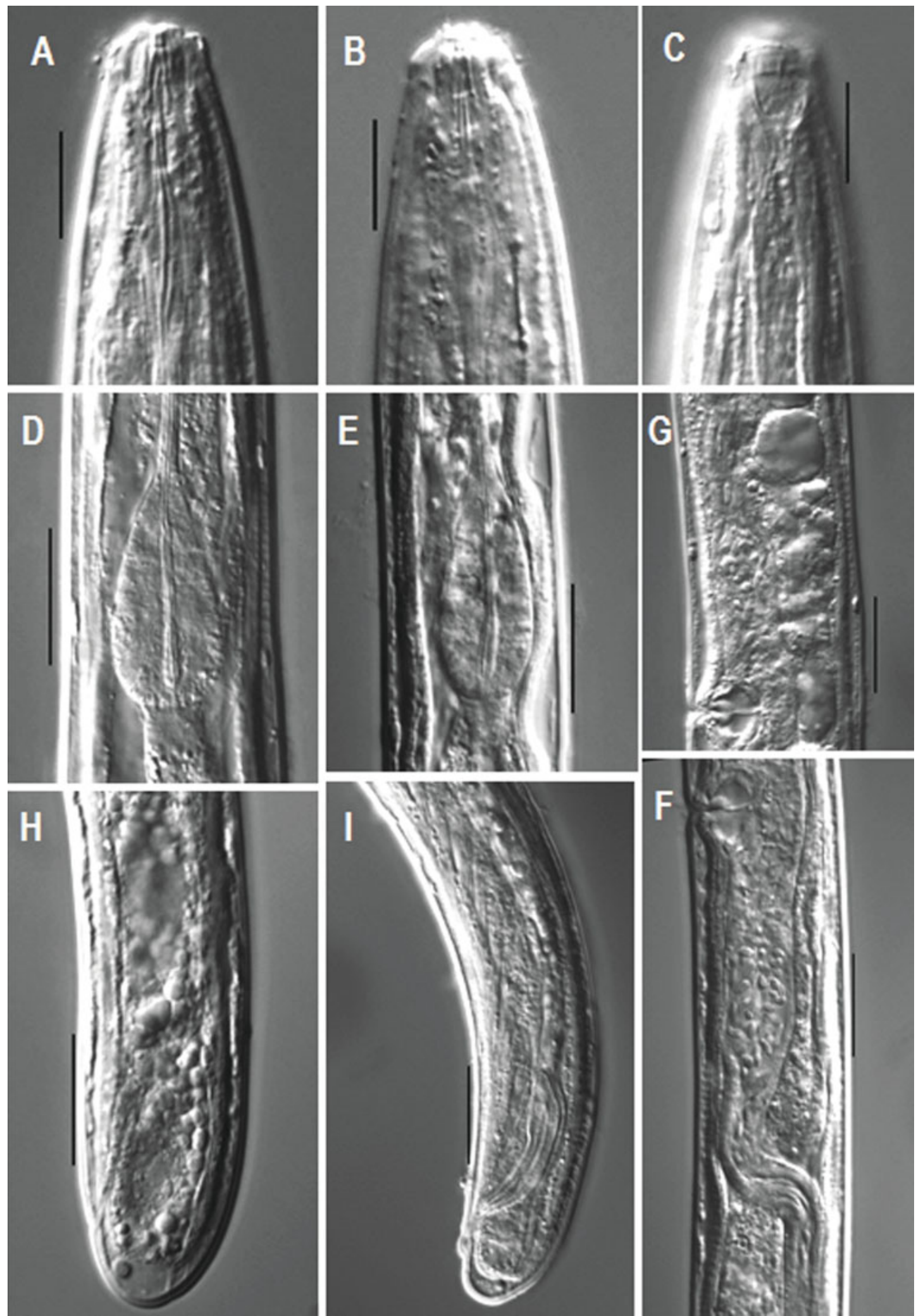

Fig. 2. Caveonchus siddiqii n. sp. (A. \& B) Anterior region; (C) anterior end showing amphid; (D. \& E) pharyngeal bulb; (F) female genital system; (G) vulval region; (H) female posterior region; (I) male posterior region. (Scale bar A-C = $10 \mu \mathrm{m} ; \mathrm{D}-\mathrm{I}=20 \mu \mathrm{m}$ ) 


\section{Results}

\section{Caveonchus siddiqii $\mathrm{n} . \mathrm{sp}$.}

(Figs. 1 \& 2)

\section{Measurements: See Tables 1}

Description: Female: Small to medium sized nematodes, slightly curved upon fixation; body cylindrical tapering slightly towards the anterior end. Cuticle with two distinct layers, $3 \mu \mathrm{m}$ thick at midbody and $3-4 \mu \mathrm{m}$ on tail. Outer layer thin; inner layer with irregular outline and loose; radial refractive elements abundant. Lateral chords occupying about $26-35 \%$ of the midbody diameter. Dorsal, ventral and lateral body pores indistinct. Lip region cap-like, offset by slight constriction, 2.2 - 2.7 times as wide as high or about one-third of the body diameter at neck base; lips rounded and amalgamated, with inner part elevated and forming a distinct perioral disc. Amphidial fovea flask-shaped, their aperture occupying about two-thirds of lip region diameter. Cheilostome a truncate cone. Odontostyle attenuate, $0.8-1.0$ times the lip region diameter long, with very narrow but distinct lumen and small aperture. Odontophore $1.2-1.5$ times the odontostyle length, slightly arcuate with basal thickening. Guiding ring simple, refractive, at 0.5 -0.6 times lip region diameter from anterior end. Pharynx consists of a slender and weakly muscular anterior part, expanding abruptly into a saccate basal bulb, occupying about $16-18 \%$ of total neck length; bearing a perceptible thickening at the posterior part of its inner lining. Cardia short and rounded to hemispherical, about one-seventh to one-fifth of the corresponding body diameter long. Nerve ring at $37-43 \%$ of neck length from anterior end. Genital system mono-opisthodelphic. Ovary reflexed, measuring $94-276$ $\mu \mathrm{m}$ long, usually not reaching the oviduct-uterus junction, however in few specimens it surpasses the oviduct-uterus junction; oocytes arranged in single row except near tip. Oviduct joining the ovary subterminally, measuring $166-219 \mu \mathrm{m}$, consisting of a slender portion and moderately developed par dilatata containing spindle-shaped sperm cells. Oviduct-uterus junction marked by weakly developed sphincter. Uterus long, tubular and often coiled in some specimens, filled with abundant sperm cells, measuring 112 - 127 $\mu \mathrm{m}$. Anterior genital branch $1.9-2.8$ times the midbody diameter long, filled with abundant sperm cells. Vagina cylindrical; pars proximalis vaginae $5-8 \mu \mathrm{m}$ long, its wall encircled by muscles; pars distalis vaginae short, 2.0 - $2.5 \mu \mathrm{m}$ long with slightly curved walls; pars refringens absent. Vulva apparently a transverse slit. Prerectum 2.9-5.2 and rectum 0.8 - 1.1 times anal body diameter long. Tail short, rounded, hemispheroid, $0.5-0.7$ times anal body diameter long, with a distinct terminal caudal pore.

Male: General morphology similar to female except for the posterior body region being more ventrally curved. Sperms spindle-shaped. Supplements an ad-cloacal pair, situated at $10 \mu \mathrm{m}$ from cloacal aperture, and three ventromedians, located outside the range of spicules, first ventromedian supplement located at $43-46 \mu \mathrm{m}$ from ad-cloacal pair. Spicules $1.1-1.5$ times cloacal body diameter long. Lateral guiding pieces very prominent, 0.28 0.37 times the spicule length. Tail short, rounded, hemispheroid, $0.5-0.7$ anal body diameter long.

Type habitat and locality: Soil samples collected from the grassland of the Kaziranga National Park, Assam, India

Other habitat and locality: Soil around the roots of grasses (unidentified) from Koibuchimachi, Mito C., Ibaraki, Japan. Collected by Dr. M. Araki on December 7, 2011.

Type specimens: Holotype female on slide Caveonchus siddiqii n. sp. / 1; paratype females on slides Caveonchus siddiqii n. sp. / 2 - 14 and males on slide Caveonchus siddiqii n. sp. / 15 - 24; deposited with the nematode collection of the Department of Zoology, Aligarh Muslim University, India.

Etymology: The new species is named after Dr. Mohammad Rafiq Siddiqi in recognition of his contribution to nematode taxonomy.

Diagnosis and relationships: Caveonchus siddiqii $\mathrm{n}$. $\mathrm{sp}$. is characterized by having a medium sized body ( $L=0.86-1.12 \mathrm{~mm})$; labial disc present; lip region cap-like, offset by slight constriction; Amphidial fovea flask-shaped, their aperture occupying about twothirds of lip region diameter; odontostyle $8-9 \mu \mathrm{m}$, odontophore 10 - $12 \mu \mathrm{m}$; pharynx with slender anterior part which expands abruptly into the saccate basal bulb, occupying about $16-21 \%$ of total neck length; female genital system mono-opisthodelphic; anterior genital branch $70-100 \mu \mathrm{m}$ or $1.9-2.8$ times the midbody diameter long; tail short, rounded, hemispheroid, $0.5-0.7$ anal body diameter long; spicules 30 - $38 \mu \mathrm{m}$ long; and three spaced ventromedian supplements.

In the presence of a perioral region with labial disc, attenuate odontostyle with narrow but distinct lumen, arcuate odontophore and pharyngeal bulb bearing a perceptible thickening at the posterior part of its inner lining, the new species comes close to C. colombicus Siddiqi, 1982; C. saccatus (Goseco, Ferris and Ferris, 1981) Siddiqi, 1982 and C. ferrisae Pedram, Pourjram and Peña-Santiago, 2012. However, it differs from the former, in having lip region offset by slight constriction (vs offset by sudden expansion); lower 'c' ratio ('c'= 53.9 - 94 vs 107 - 178; tail length 11 - 18 vs 8.5 $\mu \mathrm{m})$; smaller odontophore ( 9 - 11 vs $13-16 \mu \mathrm{m})$; anterior vulva position ( $V=37.5$ - 43 vs 46 - 54); longer spicules ( 30 - 38 vs 27 $28 \mu \mathrm{m}$ ) and presence of three ventromedian supplements ( $v s$ two ventromedian supplements).

From $C$. saccatus, it differs in having slightly longer body size $(0.86$ -1.12 vs $0.67-0.92 \mathrm{~mm}$ ); lip region offset by a slight constriction (vs offset by deep constriction); odontostyle attenuate, with narrow but distinct lumen all along the length (vs odontostyle attenuate, with very narrow lumen not all along its length); lip region slightly wide $(9-11$ vs $8.0-8.8 \mu \mathrm{m})$; longer pharyngeal bulb $(33-41$ vs $30-34 \mu \mathrm{m})$; vulva anteriorly located ( $V=37-43$ vs $44-45)$, and male present (vs absent).

The new species is very close to $C$. ferrisae, but both the populations of the new species could easily be differentiated from the Iranian species in the shape of their amphideal fovea and the size and nature of odontostyle. The lip region is although very similar 


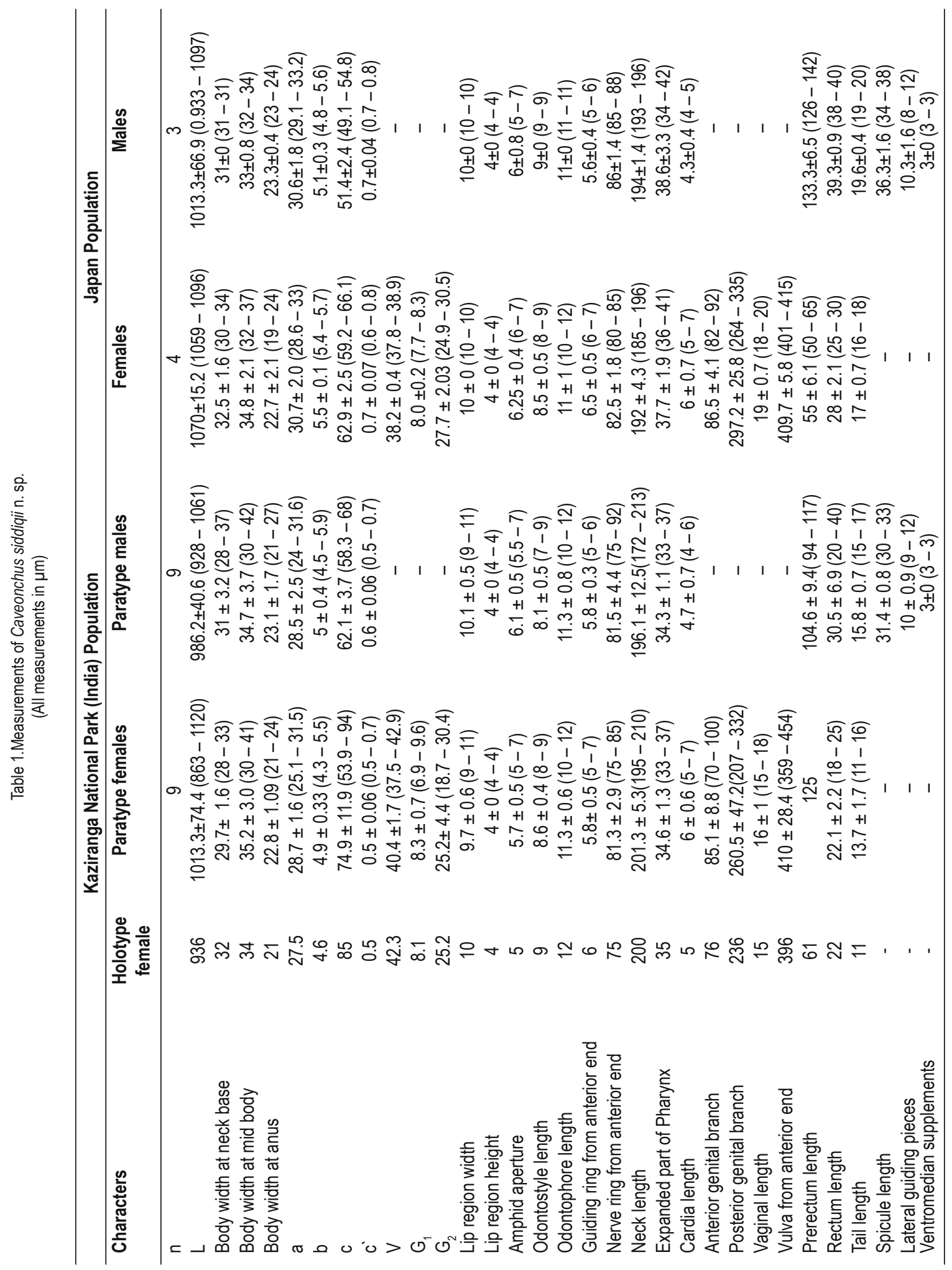




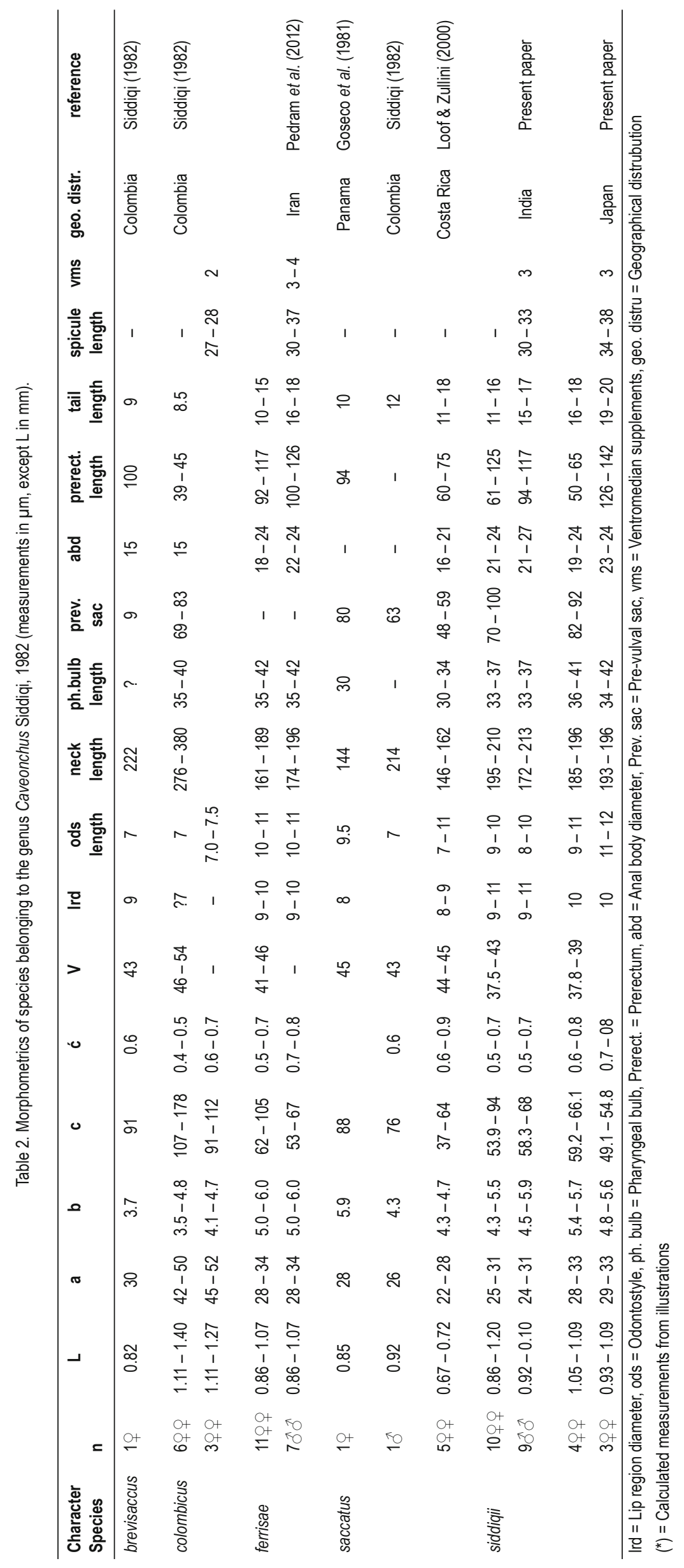


but is rather more conical and slightly offset (vs almost continuous with the body and rather rounded); amphideal fovea flask-shaped (vs amphideal fovea cup-shaped); odontostyle shorter (8 - $9 \mu \mathrm{m}$ vs $10-11 \mu \mathrm{m}$ ) and attenuate, with very narrow but distinct lumen all along the length (Fig. 2A,B) (vs odontostyle attenuate, with very narrow but distinct lumen at least along two-thirds of the its length, anterior third solid appearing Fig. 1C,D and Fig 2C,D in C. ferrisae); odontostyle shorter than lip region diameter (vs equal to or little longer than lip region diameter in C. ferrisae).

\section{Acknowledgments}

The authors are to Dr. Masaki Araki of the National Institute for Agro-Environmental Sciences, Tsukuba, Japan for kindly providing some specimens of Caveonchus sp. from his collection which was later identified as $C$. siddiqii n. sp. The first author also thanks the University Grants Commission, New Delhi for financial assistance. Part of this work was done when WA was working as INSA-JSPS visiting fellow at the NIAES, Tsukuba, Japan during summers 2012.

\section{References}

ANDRÁSSY, I. (2009): Free-living nematodes of Hungary, (Nematoda errantia) Vol. III Pedozoologica Hungarica No.5. Budapest, Hungary. Hungarian Natural History Museum \& Systematic Zoology Research Group of the Hungarian Sciences, 608

Совв, N.A. (1918): Estimating the nema population of the soil. Agricultural Technology Circular Bureau of Plant Industry, US Department of Agriculture, 1: 1 - 48

de Maeseneer, J., D' HeRde, J. (1963): Methodes utilisees pour l'etude des anguillules libres du sol. [Methods used for the study of free-living soil nematodes]. Revue de Agric. Bure., 16: 441 - 447
Goseco, C.G., Ferris, V.R., Ferris, J.M. (1981): Sclerostylus n. gen. from Panama and other neotropical species of Leptonchoidea (Dorylaimida). J. Nematol., 13: $79-86$

JAIRAJPURI, M.S. (1964): Studies on Campydoridae and Leptonchidae (Nematode: Dorylaimoidea) with description of Basirotyleptus basiri n. gen., n. sp. from India. Proc. helminth. Soc. Wash., 31: $59-64$

Loof, P.A.A., ZuLLINI, A. (2000): Free-living nematodes from nature reserves in Costa Rica. Nematology, 2: 605 - 633

LORDELLO, L.G.E. (1955): On the morphology of Proleptonchus aestivus $\mathrm{n}$. gen., n. sp. and Dorylaimus lourdesae n. sp., two new soil nematodes from Brazil. Proc. helminth. Soc. Wash., 22:71 - 75 Pedram, M., Pourjram, E., Peña-Santiago R. (2012): Description of Caveonchus ferrisae sp. n. (Dorylaimida: Leptonchidae) from northern Iran, with comments on the taxonomy of the genus. $J$. Nem. Morph. Syst., 15: $33-40$

Peña-Santiago, R (2006). Dorylaimida Part I: Superfamilies Belondiroidea, Nygolaimoidea and Tylencholaimoidea. Freshwater Nematodes, Ecology \& Taxonomy. London, MA: CABI Publishing, Wallingford, Oxfordshire $326-375$ pp.

SEINHORST, J.W. (1959): A rapid method for the transfer of nematodes from fixative to anhydrous glycerin. Nematologica, 4 : $67-69$

SIDDIQI, M.R. (1982): Seven new genera of dorylaimoid nematodes from Colombian rain forest. Syst. Parasit., 4: $69-87$

THORNE, G. (1935). Notes on free-living and plant-parasitic nematodes. Il-Higher classification groups of Dorylaimoidea. Proceedings of the Helminthological Society of Washington, 2: $96-98$

THORNE, G. (1939): A monograph of the nematodes of the superfamily Dorylaimoidea. Capita Zool., 8: 1 - 261 